\title{
POLÍTICAS PÚBLICAS Y PLANIFICACIÓN ESTRATÉGICA EN PERÚ
}

\author{
PUBLIC POLICIES AND STRATEGIC PLANNING IN PERU
}

\section{RESUMEN}

El estudio permitió examinar la trascendencia de las políticas públicas y la planificación estratégica como herramientas esenciales para resolver problemas de la sociedad, así como para orientar la visión de país a la que se aspira. El alcance del estudio fue descriptivo y la técnica de investigación, la documentación. Se propone que, para el fortalecimiento del marco institucional del planeamiento estratégico en Perú, es necesario la constitucionalización del Sistema Nacional de Planeamiento Estratégico, a fin de fortalecer la autonomía del Centro Nacional de Planeamiento Estratégico como órgano rector totalmente técnico, independiente de las oscilaciones políticas.

Palabras clave: Política; público; intervención; planificación; estrategia.
Raphael Ángel Saldaña Pacheco Ministerio de Economía y Finanzas Lima, Perú

ORCID: https://orcid.org/0000-0002-2016-3486 Correo electrónico: raphaelsaldana@gmail.com

NoÉ RodríGuez AsCue Universidad San Antonio de Abad del Cusco Cusco, Perú ORCID: https://orcid.org/0000-0003-3970-0365 Correo electrónico: noerodrigueza1948@gmail.com

Vladimir RodríGuez Cairo Universidad Nacional Mayor de San Marcos Lima, Perú

ORCID: https://orcid.org/0000-0001-9971-0405 Correo electrónico:vrodriguezc@unmsm.edu.pe

[Recibido: 30/06/2020 Aceptado: 24/08/2020 Publicado: 31/08/2020]

\begin{abstract}
The study allowed examining the importance of public policies and strategic planning as essential tools to solve society's problems, as well as to guide the vision of the country to which it aspires. The scope of the study was descriptive and the research technique, the documentation. It is proposed that, in order to strengthen the institutional framework for strategic planning in Peru, the constitutionalization of the National Strategic Planning System is necessary, in order to strengthen the autonomy of the National Center for Strategic Planning as a fully technical governing body, independent of political oscillations.
\end{abstract}

Keywords: Politics; public; intervention; planning; strategy.

(c) Los autores. Este artículo es publicado por la Revista Quipukamayoc, Universidad Nacional Mayor de San Marcos. Este es un artículo de acceso abierto, distribuido bajo los términos de la Licencia Creative Commons Atribución-NoComercial-Compartirlgual 4.0 Internacional.(http://creativecommons.org/licenses/by-nc-sa/4.0/), que permite el uso no comercial, distribución y reproducción en cualquier medio, siempre que la obra original sea debidamente citadas. 


\section{INTRODUCCIÓN}

En la actualidad, un gran número de países modernos se plantean propósitos claros, y a la vez, saben cómo lograrlos. Para tal efecto, recurren a dos herramientas fundamentales: a) análisis-debate-diseño-aprobación de políticas públicas, y b) planeamiento estratégico. Dentro de este contexto, las políticas públicas son acciones del Estado que buscan resolver problemas o necesidades de la sociedad. A través de ellas, se toman decisiones en el presente, con miras hacia el futuro, con el objeto de dar respuesta fundamentalmente a las siguientes interrogantes: ¿para qué realizar esa acción pública? (Objetivo), ¿qué acción pública debe realizarse? (Intervención pública), ¿cómo hacerlo? (Gestión estratégica pública), ¿quién debe hacerla? (Responsabilidades de los órganos del Estado juntamente con la sociedad civil) y ¿cuándo debe hacerse? (Horizonte temporal).

De manera similar, la planificación estratégica es una técnica de intervención del Estado que busca establecer los grandes lineamientos para el logro de un orden global abstracto que asegure a los miembros de una nación, las mejores posibilidades de alcanzar sus propios fines. Se trata de un conjunto de procedimientos y actividades que ejercen los diversos órganos que conforman la Administración Pública y se llega a instrumentalizar a través de medios normativos y metodológicos. En ese entender, las herramientas antes señaladas implican algún grado de intervención del Estado en la economía. No obstante, es importante circunscribir dichas intervenciones dentro de los límites del Gobierno, esto es, el principio orientador debe ser el rol subsidiario del Estado en la actividad económica. Es más, la doctrina defendida por los liberales admite un mínimo de intervención del Estado.

Se trata pues, en buena cuenta, según Sunstein (2018) que "todo sistema de mercado libre depende de un conjunto de normas jurídicas que establecen quién puede hacer qué y de la exigibilidad de esos principios por parte de los tribunales" (p. 44). Por tanto, considera que, si un nuevo sistema regulador se superpone a otro, es necesario evaluarlo según su efectividad para disminuir o aumentar la libertad humana. Dentro de este marco, se formula la siguiente pregunta: ¿Cuál es el contenido y la importancia de las políticas públicas y la planificación estratégica? Así, el objetivo de la presente investigación fue analizar el contenido y la importancia de las políticas públicas y la planificación estratégica en el Perú.

\section{Políticas públicas}

La formulación de políticas públicas inicia con el diseño que sustenta la acción pública. El diseño de una política pública es un plan, estrategia que desarrollan las autoridades con el objetivo de lograr un propósito específico. En ese sentido, una política pública es toda acción u omisión del Estado que tiene como propósito fundamental resolver problemas o necesidades de la sociedad. De manera que, no solamente supone hacer algo dentro de un nivel de gobierno, sino también dejar de hacer aquello que podría ser realizado. Por tanto, la política pública determina y procura alcanzar un fin. Siendo así, la acción pública implica, siempre y a la vez, decidir, elegir y renunciar a algo que se podría haber realizado. Ese accionar del Estado recae en autoridades que detentan el poder político y tienen poder decisorio.

Cabe precisar que el Estado es un orden construido que se formó a través del diseño humano, y como todo orden construido, establece ciertos propósitos, sin embargo, estos deben orientarse a mejorar las posibilidades de todos los miembros de una nación de perseguir con éxito sus propios fines, y en limitar el uso de la coacción.

En la estructura del Estado existen diversos órganos que lo conforman, los cuales tienen discrecionalidad en su accionar. Es así que dichos órganos, como titulares de las potestades o competencias que se establecen en la Constitución, quedan habilitados para decidir entre las alternativas que correspondan. Desde esa perspectiva, Rubio (2006) expone:

La discrecionalidad es el margen de arbitrio que el Derecho da a los órganos y organismos del Estado para ejercitar sus competencias, en atención a los fines para los que fueron establecidas y en atención al interés público [...]. El ejercicio de la discrecionalidad debe ser siempre motivado sobre la base de la razonabilidad y proporcionalidad. (p. 115)

De ahí que, si bien resulta trascendente limitar la discrecionalidad en materia económica, no es factible eliminarla del todo. Por consiguiente, las potestades atribuidas a los diversos órganos públicos en materia económica deben ser claras, de tal forma que el accionar de estos no termine afectando u obstaculizando la economía de mercado.

Por consiguiente, toda política pública que implique algún tipo de intervención en las actividades económicas de un país debe regirse por dos principios esenciales: la subsidiariedad económica del Estado y la libertad económica. El primero garantiza que el ejercicio del poder político o accionar del gobierno de turno sea limitado y que su participación sea de manera excepcional ante la inacción de los agentes privados. El segundo implica legalizar la libertad económica para promover la creatividad y la iniciativa privada. La libertad económica también implica que los agentes privados deban actuar con responsabilidad en el ejercicio de sus derechos y obligaciones en los ámbitos de libertad que se les reconozca. 
Marco institucional y política pública

North (1993), argumenta que las instituciones son fundamentales para el buen desempeño económico de un país. A su vez, Ostrom (2015) considerando la diversidad de situaciones existentes, plantea que "las arenas de acción incluyen dos holones: una situación de acción y el participante en esa situación" (p. 52). Por ello, existe una inmensidad de arenas de acción donde se dan interacciones sociales: familia, barrio, órganos del Estado en los ámbitos nacional (Ejecutivo, Legislativo y Judicial, así como los órganos constitucionales autónomos), regional y local, empresas, mercados, y en las interacciones entre todas estas arenas de manera conjunta.

En esa línea Arias y Caballero (2003), plantean la implicancia de las reglas políticas en el resultado político. Sostienen que $y=f(x)+e$, donde " $y$ " es el resultado político, " $\mathrm{x}$ " son las reglas políticas e instituciones, $\mathrm{y}$ " $\mathrm{e}$ " es un factor aleatorio.

Siendo así, en la Figura 1 se puede apreciar cómo las instituciones y organizaciones políticas son fundamentales para establecer incentivos adecuados en la sociedad, de tal manera que ello se vea reflejado en el accionar de la política pública (Ver Figura 1).
Definitivamente, toda intervención del Estado en la economía debe ceñirse al diseño de políticas públicas enfocadas en mantener o incrementar la libertad de elección personal. Desde tal perspectiva, a efectos de mejorar la gobernanza, la coacción arbitraria debe ser sustituida por incentivos y nudges.

\section{Fallas de mercado y papel del Estado}

Las fallas surgen por las imperfecciones que presentan los mercados y justifican la intervención estatal. De manera que, el Estado puede ayudar a resolver dichas fallas mediante la regulación de las actividades económicas que presentan ineficiencias. Stiglitz y Rosengard (2015) consideran que las fallas de mercado tienen muchas causas, pero seis son muy relevantes y justifican la intervención estatal en los mercados, incluso cuando estos son eficientes: falla de la competencia, bienes públicos, externalidades, problemas de información, mercados incompletos, paro, inflación y desequilibrio (déficit público).

No obstante, para Sunstein (2017), debe añadirse los fallos conductuales del mercado a la clase de justificaciones para la intervención del gobierno. Sobre esto último, sostiene que "los funcionarios del gobierno pueden mejorar la vida de la gente si están alerta de los fallos conductuales del

\section{Incentivos}

\section{Marco institucional}

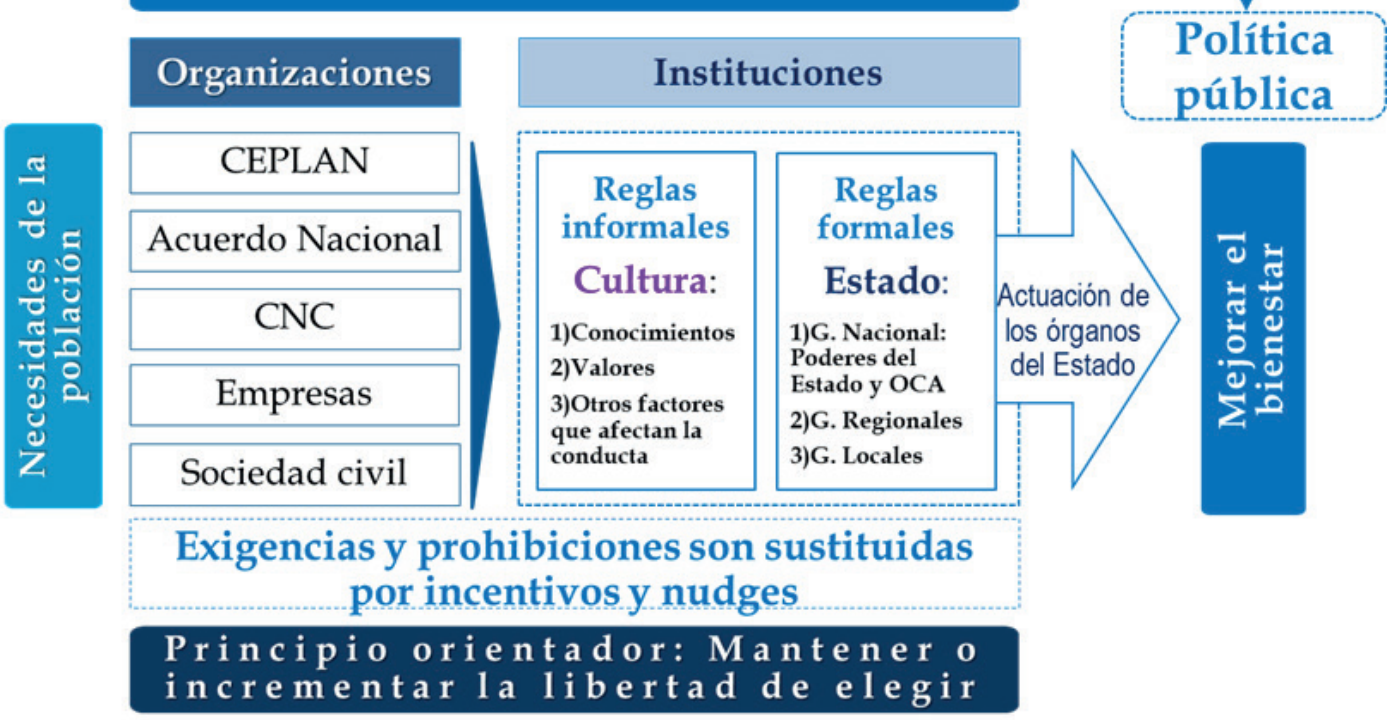

Figura 1. Marco institucional y política pública.

Fuente: Elaboración propia. 
mercado y diseñan arquitecturas de la elección que proporcionen salud, riqueza y bienestar" (p. 82). Por tanto, la intervención del Estado en la economía es excepcional y su actuación se justifica por la existencia de fallas de mercado, esto en virtud de que el rol fundamental del Estado es fomentar, estimular, coordinar y complementar las iniciativas privadas. Al respecto, Rubio (2013) añade que "la intervención estatal es reguladora porque corrige fallas, pero supletoria porque no interviene sino en el caso en que el sector privado mismo no pueda corregir tal situación" (p. 58).

No obstante, la regulación también incurre en fallas, de ahí que los principales problemas que generan las fallas en la regulación son:

- Riesgos de captura del regulador.

- Problemas de asimetría de información entre el Estado y el sector privado.

- Problemas de poder relativo desigual de las mayorías o minorías (beneficios concentrados y costos difundidos).

- Riesgo de gestión de intereses en la administración pública ante políticos o funcionarios.

- La agenda personal de los propios funcionarios.

- Tentación de aprovechar en su beneficio personal los márgenes de la discreción.

Por tal razón, Sunstein (2014), postula que "la regulación es a menudo confusa, incoherente, redundante y excesiva. Necesitamos hacer mucho más para simplificarla y reducirla" (p. 45). Considera que una buena arquitectura de la decisión ordena la labor de los reguladores; es decir, sostiene que necesitamos la arquitectura de la decisión para los arquitectos de las decisiones.
A su vez, Pinzón (2016) alude que "una mejor regulación permite construir marcos institucionales que contribuyen a cumplir sus objetivos [...]. Pero dada la necesidad de considerar los fines y los medios, no basta que la ley sea eficaz para cumplir esos objetivos, también debe ser eficiente" (p. 217).

Por lo expuesto, para regular eficaz y eficientemente, el Estado debe enfocarse en:

- Suponer o reflejar las condiciones que se darían en un mercado libre y competitivo.

- Como regla debe dejar que los mecanismos de mercado funcionen solos; si estos fallan, debe igualmente recurrir a instrumentos de mercado; $y$ solamente si esto último no funciona, debe intervenir a través de normas específicas.

- Regular es encontrar los incentivos adecuados para que los regulados se comporten como lo harían en una situación de competencia, no porque son forzados, sino porque perciben que es lo más conveniente para ellos.

Evaluación de un programa público: disyuntiva entre equidad y eficiencia

De acuerdo con Stiglitz y Rosengard (2015) "la disyuntiva entre la equidad y la eficiencia constituye el núcleo de muchos de los debates sobre la política pública” (p.222).

Siendo así, el debate gira en función a dos aspectos ¿a cuánta eficiencia se tiene que renunciar para disminuir la desigualdad?, y ¿qué valor debe asignarse a una disminución de la desigualdad en comparación con una disminución de la eficiencia?

En la Figura 2 se aprecian los cuatro escenarios o casos que se presentan al momento de diseñar políticas públicas.

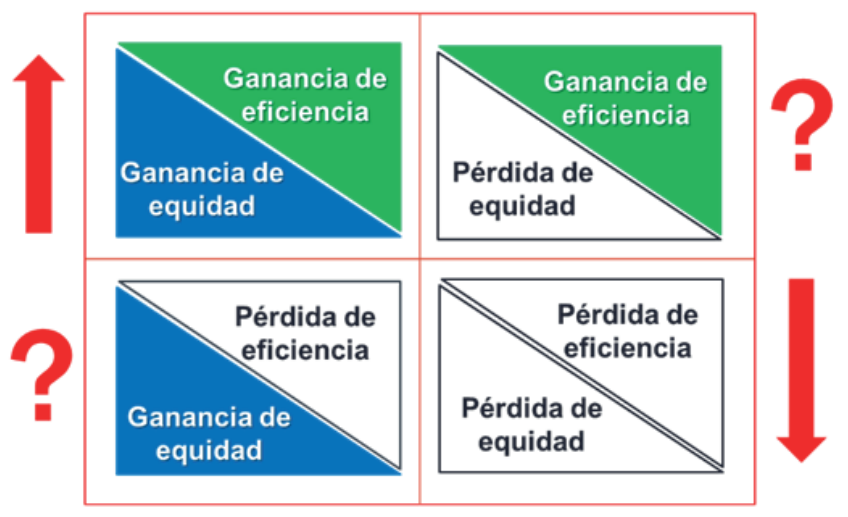

Figura 2. Disyuntiva entre eficiencia y equidad. Fuente: Elaboración propia. 
De lo anterior se desprende que, con bastante frecuencia hay un trade-off entre equidad y eficiencia, esto es, las políticas públicas que promueven la equidad, a menudo tienen un costo en términos de eficiencia, y viceversa. En efecto, si la política pública implica ganar eficiencia y equidad, no habría cuestionamiento alguno, y consiguientemente, la medida sería aprobada. De manera similar, si la política pública implica pérdida de eficiencia y equidad, simplemente se rechaza la medida propuesta. Sin embargo, el problema surge en las otras dos situaciones: cuando la política pública implica ganancia de eficiencia y pérdida de equidad, o pérdida de eficiencia y ganancia de equidad. Justamente estos dos casos son los que deben sopesarse a efectos de tomar la mejor decisión. Claro está que los recursos deben utilizarse tan eficientemente como sea posible para alcanzar los objetivos de la sociedad.

Por ejemplo, Peña (2004), al referirse a la educación superior, aborda esta disyuntiva, afirmando que "una mejor asignación de recursos es un avance en la eficiencia, en cuanto aumenta la cobertura y la calidad con recursos fiscales limitados. Una mejor distribución vertical y horizontal de la cobertura y la calidad es un avance en la equidad, suponiendo recursos fiscales ilimitados" ( $\mathrm{p}$. 129). Pero, además, precisa que debido a la precariedad de recursos con que cuentan los países de ingreso medio como Colombia, la disyuntiva entre eficiencia y equidad se resuelve en favor de la primera opción, y se fija como criterio en la formulación de políticas.

\section{Planificación estratégica}

Planificar es elaborar el plan o proyecto de una acción, es decir, es algo que se realiza antes de efectuar una acción, es tomar una decisión de manera anticipada. Esto involucra establecer objetivos claros y los objetivos claros permiten ser eficaces. De ahí que la planificación es un proceso que utiliza recursos humanos, materiales $y$ financieros y busca alcanzar diversos objetivos y metas previstos a través del plan.

En cuanto a las posiciones sobre el propósito de la planificación, Ariño (2004) señala que "la planificación es una técnica de intervención de la actividad económica por la cual la Administración pretende encauzar, racionalizar o someter a un diseño previo la actividad económica, en función de aquello que se considere necesario o beneficioso para el conjunto del país" (p. 377). Así, también Dromí (2005) alude que "la planificación es necesaria para obtener mayor producción y más equitativa distribución de la riqueza. La planificación es, pues, la manifestación de la pretensión humana para ordenar racionalmente su convivencia" (p. 282).

En esa orientación, la planificación estratégica es un proceso dinámico y continuo que consiste en proyectar un futuro deseado y los medios efectivos para lograrlo. En estricto, busca alinear los objetivos de la sociedad con una visión de futuro, esto es, apunta a alcanzar el desarrollo económico y social de manera integral. El resultado de la planificación estratégica es tener una organización focalizada en el ciudadano que genere valor y utilice mejor los recursos escasos con una prospectiva articulada de largo plazo. Para ello es necesario cambiar la mentalidad, no solo elaborar planes.

Uno de los roles fundamentales del Estado es asegurar la libre competencia en el mercado.

La competencia es un orden espontáneo que proviene de las acciones humanas individuales, y como tal, es el mecanismo más efectivo para promover la asignación eficiente de los recursos en el mercado. Con el mismo énfasis se debe precisar que, la planificación y la competencia sólo pueden combinarse para planificar la competencia, pero no para planificar contra la competencia (Hayek, 2011).

Por tanto, pueden coexistir planificación y competencia, a tal punto de considerar relevante la planificación para mantener o incrementar la competencia. Es más, Hayek enfoca su crítica contra la planificación que busque distorsionar la competencia, es decir, la planificación centralizada. En efecto, de lo que se trata es de promover y vigilar la libre competencia, ya que con ello se garantiza el buen funcionamiento de los mercados. Para tal efecto, el Estado a través de la planificación estratégica debe fortalecer la libre competencia, impidiendo aquellas prácticas que la restrinjan, así como la competencia desleal.

Obviamente, el buen funcionamiento de la libre competencia requiere, y depende, de ciertas condiciones que nunca pueden ser totalmente garantizadas por las empresas privadas. Ante esta situación, resulta necesaria y pertinente la intervención del poder público. Por lo tanto, queda claro que la planificación estratégica y la competencia solo pueden combinarse cuando se planifica para la competencia, no en contra de ella.

Debe quedar claramente establecido que en la planificación centralizada se deja de lado al individuo y, por el contrario, son los representantes o burócratas del Estado los que terminan decidiendo acerca de las prioridades de la población en su conjunto. Justamente, este tipo de planificación centralizada es bastante peligrosa porque obedece a la voluntad del racionalismo constructivista de los gobiernos de turno, el mismo que no resulta compatible con el mercado ni con la competencia.

Bajo tales premisas, la planificación tal como hoy se la concibe, esto es, la planificación estratégica, exige la coordinación previa entre los diferentes órganos que conforman la Administración Pública en los diversos sectores 
económicos. Desde esta perspectiva, un aspecto primordial que se debe tomar en cuenta es la revisión constante de los lineamientos establecidos a efectos de poder encauzar de manera efectiva la visión conjunta del país.

Ahora bien, la planificación debe garantizar la provisión de los bienes y servicios públicos, pero en ninguna circunstancia debe vulnerar la libertad de elegir de los ciudadanos y, por tanto, no debe distorsionar los intercambios en el mercado. De este modo, los procedimientos establecidos en los diversos medios normativos y metodológicos deben ser claros a tal punto de establecer la responsabilidad de las entidades involucradas. Asimismo, un aspecto esencial es el involucramiento de los altos funcionarios de los diversos órganos del Estado y su coordinación con las respectivas áreas de planificación y presupuesto.

En síntesis, la planificación estratégica exige:

- Comprender la estructura y funcionamiento de los mercados.

- Identificar si existe o no fallas del mercado para corregirlas.

- Analizar los riesgos de incurrir en fallas regulatorias que obstruyan el funcionamiento de los mercados o la competencia.

- Determinar si la intervención del Estado mejora la eficiencia o la equidad, o ambas.

- Evaluar si el costo de la intervención es o no mayor que la falla de mercado que esa intervención busca corregir.

Políticas de estado y políticas nacionales como dimensiones de la planificación estratégica en Perú

La planificación estratégica puede concebirse en dos dimensiones: una espacial y otra sectorial. En efecto, para Dromí (2005):

La primera está dada por los alcances territoriales del plan, y así tenemos planes nacionales, regionales, provinciales, municipales. La dimensión sectorial hace referencia al contenido del plan, y así existen planes estrictamente especializados, como, por ejemplo, plan energético, siderúrgico, vial, etc., que en un proceso de sumatoria conforman el plan nacional (p. 286).

En Perú, de conformidad con el artículo 46 de la Ley Orgánica del Poder Ejecutivo: El Planeamiento Estratégico es un sistema administrativo que se rige por la ley de la materia. Como sistema administrativo, está conformado por un conjunto de reglas orientadas al desarrollo de la planificación estratégica en el país (Ley N²9158, 2007).
Dentro de este marco, el Sistema de Planeamiento Estratégico en Perú comprende:

1. Sistema Nacional de Planeamiento Estratégico (SINAPLAN) y Centro Nacional de Planeamiento Estratégico (CEPLAN)

El SINAPLAN es el conjunto articulado e integrado de órganos, subsistemas y relaciones funcionales cuya finalidad es coordinar y viabilizar el proceso de planeamiento estratégico nacional para promover y orientar el desarrollo armónico y sostenido del país. Está integrado por: a) El CEPLAN, como órgano rector del Sistema; b) Los órganos del gobierno nacional y los demás poderes del Estado, organismos constitucionales autónomos y gobiernos regionales y locales con responsabilidades y competencias en el planeamiento estratégico; y c) El Foro del Acuerdo Nacional.

En el caso peruano, el CEPLAN, es el organismo técnico especializado que ejerce la función de órgano rector, orientador y de coordinación del Sistema Nacional de Planeamiento Estratégico (SINAPLAN); orientado al desarrollo de la planificación estratégica como instrumento técnico de gobierno y gestión para el desarrollo armónico y sostenido del país y el fortalecimiento de la gobernabilidad democrática en el marco del Estado constitucional de derecho. (Centro Nacional de Planeamiento Estratégico, 2020)

El CEPLAN se encuentra adscrito a la Presidencia del Consejo de Ministros (Decreto Legislativo No 1088), y no necesariamente se caracteriza por ser estable en términos políticos, ya que con bastante frecuencia se realizan cambios en el cargo de presidente del Consejo de Ministros, lo cual termina debilitando el sistema de planeamiento estratégico en Perú. Al respecto, se considera que debido a la implicancia que tiene para un país, el Sistema Nacional de Planeamiento Estratégico debería ser un órgano totalmente técnico y alejado de cualquier oscilación política de los gobiernos de turno.

2. Políticas de alcance nacional. Cabe precisar que "son políticas de alcance nacional, aplicables en todo el territorio, las Políticas de Estado y las Políticas Nacionales" (Decreto Supremo No 029-2018-PCM).

a. Políticas de Estado

El numeral 6.1 del artículo 6 prescribe lo siguiente:

Las políticas de Estado definen lineamientos generales que orientan el accionar del Estado en el largo plazo a fin de lograr el bienestar de los ciudadanos y 
el desarrollo sostenible del país [...]. Están contenidas en el Acuerdo Nacional y se concretan en el Plan Estratégico de Desarrollo Nacional (Decreto Supremo No 029-2018-PCM).

El Acuerdo Nacional es el "conjunto de políticas de Estado elaboradas y aprobadas sobre la base del diálogo y del consenso, [...], con el fin de definir un rumbo para el desarrollo sostenible del país y afirmar su gobernabilidad democrática" (Acuerdo Nacional, 2014).

El Acuerdo Nacional ha aprobado 31 Políticas de Estado, que han sido agrupadas en cuatro objetivos: i) Fortalecimiento de la Democracia y Estado de derecho, ii) Desarrollo con Equidad y justicia social, iii) Promoción de la Competitividad del país, iv) Afirmación de un Estado eficiente, transparente y descentralizado.

\section{b. Políticas Nacionales}

El numeral 8.1 del artículo 8 dispone que: "Las Políticas Nacionales constituyen decisiones de política a través de las cuales se prioriza un conjunto de objetivos y acciones para resolver un determinado problema público de alcance nacional y sectorial o multisectorial en un periodo" (Decreto Supremo No 029-2018-PCM).

Los respectivos ministerios diseñan, establecen, ejecutan y supervisan políticas nacionales y sectoriales bajo su rectoría, las cuales aplican a todos los niveles de gobierno. El cumplimiento de las políticas nacionales y sectoriales del Estado es de responsabilidad de las autoridades del gobierno nacional, los gobiernos regionales y los gobiernos locales.

Las políticas sectoriales es el subconjunto de políticas nacionales que afecta una actividad económica y social específica pública o privada. Al respecto, cabe señalar que "las Políticas Nacionales se enmarcan en las Políticas de Estado, la Política General de Gobierno y los objetivos del Plan Estratégico de Desarrollo Nacional" (Decreto Supremo No 029 2018-PCM) y pueden ser:

i. Políticas Nacionales Sectoriales, "corresponden al subconjunto de políticas nacionales acotadas a una determinada actividad económica y social específica pública o privada, bajo el ámbito de competencia de un Ministerio" (Decreto Supremo No 029-2018-PCM). La rectoría de una política nacional sectorial es la potestad exclusiva de un ministerio para prio- rizar la atención de problemas o necesidades públicas y disponer medidas sectoriales nacionales, que permitan alinear la actuación de los tres niveles de gobierno y de los ciudadanos, según corresponda, a efectos de alcanzar los objetivos de la política nacional sectorial adoptada, en beneficio de la ciudadanía (Decreto Supremo No 029-2018-PCM).

ii. Las Políticas Nacionales Multisectoriales, “corresponden al subconjunto de políticas nacionales que buscan atender un problema o necesidad que requiere para su atención integral la intervención articulada de más de un sector, bajo el ámbito de competencia de dos o más Ministerios" (Decreto Supremo No 029-2018-PCM).

Actualmente, existen 76 políticas nacionales en el país (Centro Nacional de Planeamiento Estratégico, 2020). Conforme al numeral 1 del artículo 4 de la Ley Orgánica del Poder Ejecutivo: El Poder Ejecutivo tiene la competencia exclusiva de diseñar y supervisar las políticas nacionales y sectoriales, las cuales son de cumplimiento obligatorio por todas las entidades del Estado en todos los niveles de gobierno (Ley $\mathrm{N}^{\circ} 29158,2007$ ).

Debe haber concordancia entre las políticas regionales y locales con las políticas nacionales. En efecto, los gobiernos regionales y locales formulan políticas regionales y locales, en sus respectivos ámbitos territoriales, en concordancia con las políticas nacionales conforme a lo dispuesto en sus respectivas Leyes Orgánicas (Decreto Supremo No 029-2018-PCM).

Vinculación de las políticas nacionales con el SINAPLAN

Las políticas nacionales desarrollan sus objetivos a través de metas, indicadores y responsables en los respectivos planes estratégicos sectoriales multianuales, planes estratégicos multisectoriales, planes estratégicos institucionales y planes operativos institucionales de los $\mathrm{Mi}$ nisterios y sus organismos públicos, según corresponda, en el marco del SINAPLAN (Decreto Supremo No 0292018-PCM).

\section{Política General de Gobierno}

Otro instrumento es la Política General de Gobierno: conjunto de políticas priorizadas que se desarrollan a través de políticas nacionales durante un periodo de Gobierno (Decreto Supremo No 029-2018-PCM). Está bajo la dirección del presidente de la República y debe ser presentada por el/la presidente/a del Consejo de Ministros al Congreso de la República, conforme lo dispuesto en 
la Constitución Política del Perú (Decreto Supremo No 029-2018-PCM).

En efecto, el inciso 3 del artículo 118 dispone que el presidente de la República dirige la política general del gobierno (Constitución Política del Perú, 1993). En esa orientación, la Política General de Gobierno al 2021 se desarrolla sobre cinco ejes, que se encuentran interrelacionados y que guardan consistencia con el marco de políticas y planes del país (Decreto Supremo No 056-2018-PCM). Estos ejes son: a) Integridad y lucha contra la corrupción, b) Fortalecimiento institucional para la gobernabilidad, c) Crecimiento económico equitativo, competitivo y sostenible, d) Desarrollo social y bienestar de la población, e) Descentralización efectiva para el desarrollo.

\section{Plan Estratégico de Desarrollo Nacional (PEDN)}

El PEDN denominado Plan Bicentenario: El Perú hacia el 2021, aprobado mediante Decreto Supremo N 054-2011PCM, es el documento orientador del SINAPLAN. Se fundamenta en la Declaración Universal de los Derechos Humanos, el concepto de desarrollo humano como libertad y las Políticas de Estado del Acuerdo Nacional.

El Plan Bicentenario es concebido como un instrumento de carácter orientador, flexible y abierto, que de manera permanente se enriquece a través de la dinámica social y económica del país. Se enmarca en seis ejes estratégicos: a) Derechos fundamentales y dignidad de personas, b) Oportunidades y acceso a los servicios, c) Estado y gobernabilidad, d) Economía, competitividad y empleo, e) Desarrollo regional e infraestructura, f) Recursos naturales y ambiente.

Para cada uno de ellos, el PEDN establece un objetivo estratégico nacional, lineamientos de política y objetivos específicos con indicadores y metas, acciones estratégicas, programas estratégicos y proyectos.

\section{Marco Macroeconómico Multianual (MMM)}

El MMM es el documento más relevante que el Gobierno del Perú emite en materia económica. Este documento contiene las proyecciones macroeconómicas y los supuestos en los que estás se basan, por un periodo de cuatro años, que comprende el año para el cual se está elaborando el presupuesto del Sector Público y al menos los tres años siguientes (Ministerio de Economía y Finanzas, 2020).

El Ministerio de Economía y Finanzas (MEF) es el responsable de la elaboración y publicación del MMM. El MMM es aprobado por el Consejo de Ministros, antes del 30 de agosto de cada año y es publicado íntegramente, junto con el Informe del Consejo Fiscal, dentro de los dos días hábiles siguientes a su aprobación, en El Peruano y en el portal del MEF (Ministerio de Economía y Finanzas, 2020).

\section{Política Nacional de Competitividad y Productividad (PNCP)}

La PNCP tiene como objetivo proveer las condiciones necesarias para la generación de bienestar para todos los peruanos sobre la base de un crecimiento económico sostenible con enfoque territorial.

La PNCP constituye, el hilo conductor de la política de gobierno en materia de crecimiento, con la ambición de que perdure más allá del mandato de la actual administración y se convierta en una verdadera Política de Estado, [...]. Es de cumplimiento obligatorio para todas las entidades de los diferentes Poderes del Estado, Organismos Constitucionales Autónomos y de los diferentes niveles de gobierno. También es de obligatorio cumplimiento para el sector privado y la sociedad civil, en cuanto le sea aplicable. (Consejo Nacional de Competitividad y Formalización, 2020)

El Ministerio de Economía y Finanzas (MEF), a través del Consejo Nacional de Competitividad y Formalización (CNC), conduce la Política Nacional de Competitividad y Productividad. El CNC fue creado en el año 2002 y está integrado con representantes del sector público y privado y, cuenta con una Secretaría Técnica. Tiene las siguientes funciones en materia de competitividad: detecta barreras y define prioridades estratégicas, impulsa y realiza el seguimiento de las reformas transversales, articula sectores (público, privado y académico), orienta y provee información, evalúa las políticas de competitividad, así como su implementación (Consejo Nacional de Competitividad y Formalización, 2020).

La PNCP se enmarca en nueve objetivos prioritarios (OP), tomando en cuenta tres niveles: i) nivel de articulación intra público en los tres niveles de gobierno; ii) nivel de articulación público-privado orientado al incremento de la productividad, y; iii) nivel de articulación público-privado orientado al ciudadano. Los nueve OP son: Dotar al país de infraestructura económica y social de calidad; Fortalecer el capital humano; Generar el desarrollo de capacidades para la innovación, adopción y transferencia de mejoras tecnológicas; Impulsar mecanismos de financiamiento local y externo; Crear las condiciones para un mercado laboral dinámico y competitivo para la generación de empleo digno; Generar las condiciones para desarrollar un ambiente de negocios productivo; Facilitar las condiciones para el comercio exterior de bienes y servicios; Fortalecer la institucionalidad del país; Promover la sostenibilidad ambiental en la operación de actividades económicas. 


\section{Plan Nacional de Competitividad y Productividad}

Conjunto consensuado de medidas de política transversales, las cuales se relacionan con los objetivos prioritarios de la PNCP. Las medidas forman parte fundamental de la implementación de la PNCP, [...]. Así, las medidas representan las acciones del Gobierno para la mejora de la competitividad, mediante la interacción del sector público y privado, gremios, la academia y la sociedad civil. (Consejo Nacional de Competitividad y Formalización, 2020)

El objetivo del Plan Nacional de Competitividad y Productividad es servir de enlace entre la visión de país formulada y diseñada a partir de la PNCP y la implementación de medidas de política necesarias para orientar la realidad del país hacia esa visión.

\section{Fortalecimiento de la Planificación Estratégica en Perú}

La regulación del sistema nacional de planeamiento estratégico puede instituirse a nivel constitucional, en una norma de menor jerarquía o en una combinación de ambas. Así, Dromí (2005) señala que:

La regulación jurídica del plan, como ordenamiento procedimental del quehacer público, puede hacerse tanto a nivel constitucional como infraconstitucional. La constitucionalización de la planificación es una circunstancia potestativa o no obligatoria del constituyente, que en su regulación incluso puede ofrecer un carácter preceptivo (imperativo) u optativo (facultativo) (p. 291).

No obstante, la ventaja de constitucionalizar el sistema nacional de planeamiento estratégico, dentro del cual se contemple su finalidad, estructura organizativa y competencias, es que otorga mayor autonomía al órgano rector y sobre todo mayor independencia, convirtiéndolo de esa manera, en un organismo técnico, ajeno a las oscilaciones políticas. Por ello, no solo es saludable sino imprescindible, que el Centro Nacional de Planeamiento Estratégico pase a ser parte de los Órganos Constitucionales Autónomos, caracterizados porque su autonomía no solo es reconocida en una ley orgánica sino en la propia Constitución Política.

La constitucionalización implica fortalecer institucionalmente el sistema nacional de planeamiento estratégico en Perú. De esta manera se evitaría cualquier tipo de intromisión o vulneración de la autonomía del órgano rector. Un caso que amerita resaltar es el colombiano. Su Carta Magna contempla un capítulo referido a los planes de desarrollo, se establece que "habrá un Plan Nacional de Desarrollo conformado por una parte general y un plan de inversiones de las entidades públicas del orden nacional" (Constitución Política de Colombia, 1991).
Asimismo, ordena que "las entidades territoriales elaborarán y adoptarán de manera concertada entre ellas y el gobierno nacional, planes de desarrollo, con el objeto de asegurar el uso eficiente de sus recursos y el desempeño adecuado de las funciones [...]" (Constitución Política de Colombia, 1991). De igual manera, prescribe que habrá un Consejo Nacional de Planeación integrado por representantes de entidades territoriales y sectores económicos, sociales, ecológicos, comunitarios y culturales.

Del mismo modo, la Constitución de Colombia dispone que "El Consejo tendrá carácter consultivo y servirá de foro para la discusión del Plan Nacional de Desarrollo [...]. El Consejo Nacional y los consejos territoriales de planeación constituyen el Sistema Nacional de Planeación" (Constitución Política de Colombia, 1991). Ahora bien, otra disposición es aquella que establece que "la entidad nacional de planeación [...], tendrá a su cargo el diseño y la organización de los sistemas de evaluación de gestión y resultados de la administración pública, tanto en lo relacionado con políticas como con proyectos de inversión [...]" (Constitución Política de Colombia, 1991). Esta norma constituye un mecanismo trascendente para la evaluación de la gestión y los resultados del accionar de la administración pública.

En definitiva, el hecho de constitucionalizar el sistema nacional de planeamiento estratégico, permitiría que su órgano rector forme parte de los órganos constitucionales autónomos y con ello se fortalecería la planificación en todos los niveles del Estado.

La planificación estratégica requiere reglas de juego claras a nivel constitucional. Ello permitirá establecer lineamientos orientados a garantizar un orden a través de normas constitucionales principio y normas constitucionales regla que orienten el desarrollo de las diversas actividades económicas, lo cual definitivamente debe ser compatible con el mercado. Además, dicho sistema debe contemplar incorporar la evaluación de la gestión pública por resultados.

Es indudable que, el sistema nacional de planeamiento estratégico debe constituirse en un elemento esencial del modelo económico del país que busque ordenar racionalmente el desarrollo de las actividades económicas sin distorsionar el mercado.

Un aspecto a tomar en cuenta es que una constitución política, además de establecer claramente los derechos fundamentales de una nación, racionaliza el poder. En esa línea, un argumento a favor de la constitucionalización del sistema nacional de planeamiento estratégico es la racionalización de la intervención del Estado en la economía. Desde luego, esto dista sustancialmente de la planificación centralizada que se impuso en el mundo durante los años 
setenta y ochenta, caracterizada por la intromisión del Estado en la actividad económica. Por el contrario, con la constitucionalización se busca orientar el desarrollo de las actividades económicas del país sin distorsionar el orden espontáneo del mercado, de manera que se promueve la libre iniciativa privada y se garantice la libre competencia.

\section{CONCLUSIONES}

En toda sociedad moderna existe algún grado de intervención estatal en la economía. Sin embargo, toda política pública debe diseñarse teniendo como principio orientador que las medidas a implementarse deben fundarse en mantener o incrementar la libertad de elegir de las personas, lo cual implica que no se debe constreñir la libertad de elegir. En ese entender, la planificación estratégica es una técnica de intervención pública compatible con la economía mercado, la cual presupone la adopción de ciertas medidas por parte del poder estatal, sin embargo, dicho accionar no debe implicar intromisión alguna. De ahí que resulta trascendente que las actividades estatales sean compatibles con el funcionamiento del libre mercado, que acompañen su desarrollo y fortalecimiento, pero que no se obstaculice ni se pongan trabas.

La planificación estratégica se instrumentaliza a través de medios normativos (reglas de juego que permiten institucionalizar la función administrativa) y metodológicos (procedimientos que permiten efectuar proyecciones a partir de un diagnóstico). Las dimensiones espacial y sectorial de la planificación estratégica contribuyen a aumentar la certidumbre y previsibilidad de los agentes económicos. No se pretende tan solo anticipar el futuro, sino también aumentar de manera igualitaria las posibilidades que todo miembro de la sociedad busque con éxito sus propios fines, y limitar el uso de la coacción, de tal forma que se mantengan las libertades económicas de sus miembros. Esto exige, gestionar la visión país de manera estratégica preservando las libertades económicas de todos los miembros que conforman una sociedad, y generando incentivos adecuados para orientar el accionar hacia un mismo sentido o lado.

Si bien se realizaron diversos esfuerzos por mejorar el sistema nacional de planeamiento estratégico en Perú, aún no constituye un instrumento efectivo para orientar el desarrollo armónico del país, debido a que el órgano rector a cargo de orientar la planificación, se encuentra adscrito a la Presidencia del Consejo de Ministros, cuya característica esencial es la poca continuidad de los funcionarios que la presiden, con lo cual convierte al CEPLAN en vulnerable a las injerencias o intromisiones de los gobiernos de turno. Es así que en la actualidad, el fortalecimiento del SINAPLAN exige su constitucionalización, a efectos de institucionalizar la planificación en todos los niveles del Estado y consagrar la plena autonomía del CEPLAN, como ente rector del planeamiento estratégico en el país.

\section{REFERENCIAS}

Acuerdo Nacional (2014). Políticas de Estado. [fecha de consulta: 19 de abril del 2014]. [http://acuerdonacional.pe/politicas-de-estado-del-acuerdo-nacional/ definicion/]

Arias, X. y Caballero, G. (2003). Instituciones, costos de transacción y políticas públicas: un panorama. Revista de Economía Institucional, 5(8), 117-146.

Ariño, G. (2004). Principios de Derecho Público Económico. España: Editorial Comares S.L., 1089.

Centro Nacional de Planeamiento Estratégico. Web institucional del CEPLAN. [fecha de consulta: 6 de junio de 2020]. [https://www.gob.pe/ceplan]

Consejo Nacional de Competitividad y Formalización. Plan y política. [fecha de consulta: 6 de junio de 2020]. [https://www.cnc.gob.pe]

Constitución Política de Colombia. Gaceta Constitucional, 4 de julio de 1991.

Constitución Política del Perú. Diario Oficial El Peruano, 29 diciembre 1993.

Decreto Legislativo No 1088, Decreto Legislativo que aprueba la Ley del Sistema Nacional del Planeamiento Estratégico y del Centro Nacional de Planeamiento Estratégico. Diario Oficial El Peruano, 27 junio 2008.

Decreto Supremo No 029-2018-PCM, Decreto Supremo que aprueba reglamento que regula las Políticas $\mathrm{Na}$ cionales. Diario Oficial El Peruano, 20 marzo 2018.

Decreto Supremo No 056-2018-PCM, Decreto Supremo que aprueba la Política General de Gobierno al 2021. Diario Oficial El Peruano, 23 mayo 2018.

Decreto Supremo No 054-2011-PCM, Decreto Supremo que aprueba el Plan Bicentenario: el Perú hacia el 2021. Diario Oficial El Peruano, 23 junio 2011.

Dromí, R. (2005). Derecho Administrativo. Perú: Editorial Gaceta Jurídica.

Hayek, F. (2011). Camino de servidumbre (3. ${ }^{a}$ ed.). España: Alianza Editorial.

Ley $N^{\circ}$ 29158, Ley Orgánica del Poder Ejecutivo. Diario Oficial El Peruano, 20 diciembre 2007. 
Ministerio de Economía y Finanzas (2020). Marco Macroeconómico Multianual (MMM). Recuperado del sitio web del Ministerio de Economía y Finanzas: https:// www.mef.gob.pe/es/marco-macroeconomico/marco-macroeconomico-multianualmmm

North, D. (1993). Instituciones, cambio institucional y desempeño económico. México: Fondo de Cultura Económica.

Ostrom, E. (2015). Comprender la diversidad institucional. México: Fondo de Cultura Económica.

Peña, O. (2004). La educación superior en Colombia y la teoría de los costos de transacción política. Revista de Economía Institucional, 6(11), 97-134.

Pinzón, M. (2016). Prácticas para mejorar la regulación en Colombia. Revista de Economía Institucional, 18(35), 207-228.

Rubio, M. (2013). La interpretación de la Constitución según el Tribunal Constitucional (3. ${ }^{a}$ ed.). Lima; Fondo Editorial PUCP.
Rubio, M. (2006). El Estado peruano según la jurisprudencia del Tribunal Constitucional. Perú: Fondo Editorial de la Pontificia Universidad Católica del Perú.

Stiglitz, J. y Rosengard J. (2015). La Economía del Sector Público (4. ${ }^{a}$ ed.). España: Antoni Bosch, editor S.A.

Sunstein, C. (2018). Las cuentas pendientes del sueño americano. Por qué los derechos sociales y económicos son más necesarios que nunca. Argentina: Siglo Veintiuno Editores Argentina S.A.

Sunstein, C. (2017). Paternalismo libertario. Barcelona: Herder Editorial.

Sunstein, C. (2014). (más) Simple. El futuro del gobierno. Madrid: Marcial Pons Ediciones Jurídicas y Sociales S.A. 
